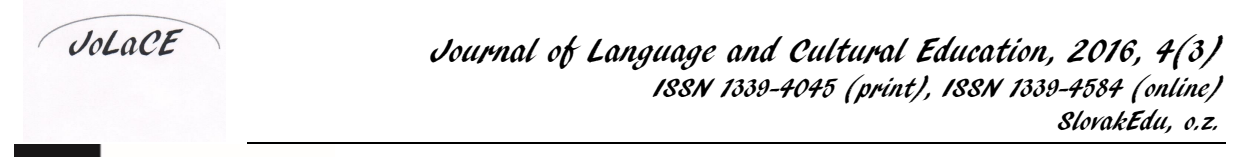

$\frac{\text { DE }}{G}$

DOI: $10.1515 /$ jolace-2016-0032

\title{
EFL teacher professional change in India
}

\author{
Helen B. Toraskar, Centennial College (HKU Group), Hong Kong \\ Helen.toraskar@Centennialcollege.hku.hk
}

\begin{abstract}
This article examines teacher professional change and compares two $10^{\text {th }}$ standard English as a Foreign Language teachers employed in a Marathi-medium secondary school in Pune (India) at different stages in their careers. Wenger's (1998) three interconnected Community of Practice dimensions (i.e. mutual engagement, joint enterprise and shared repertoire) highlight pertinent facets of the teachers' professional lives as viewed from the sociocultural perspective (Vygotsky, 1978). Case study methodology was utilized within a qualitative, ethnographic research paradigm. The aim is to uncover how the two EFL teachers engage in their professional community of practice and their career trajectories. Firstly, the data analysis indicates that periphery member status is established through active engagement in the professional community which creates trajectories along which novices may travel. Secondly, the accessing and sharing of information, ideas and experiences is beneficial for all members as it strengthens professional relationships and reconfirms already existing members' central position. Lastly, active engagement in a professional community of practice offers a means of potential growth for novice teachers and central members. Access to communal resources such as new knowledge, stories and artifacts is acquired and aids in establishing novices' competency.
\end{abstract}

Key words: Sociocultural perspective; professional community of practice; EFL teaching; novice EFL teacher; professional change

\section{Introduction}

This study focuses on two tenth standard EFL teachers, namely Mr. L. (an expert EFL teacher) and Mrs. So (a novice EFL teacher), who are at different stages in their teaching careers in the same Marathi-medium secondary school in the Pune district. The school in this study adheres to the tenth standard syllabus for English as a third language in Maharashtra. The aim is to understand the transformation they have experienced during their professional lives and to demonstrate how these experiences have contributed to such change. Professional transformation is examined through the lens of mutual engagement, joint enterprise and shared repertoire which Wenger (1998) identified as three 
interconnected dimensions of a Community of Practice (CoP). These elements are employed to highlight significant facets of the teachers' professional lives from the sociocultural perspective (Vygotsky, 1978).

Thus, the stance adopted here is that learning to teach is a developmental process which is dialectical in nature and which is embedded within the sociocultural context. Of significance is that the process of transformation is not envisioned as a group of isolated incidents occurring one after the other. Teacher transformation arises from the tension that exists between two elements (i.e. "social competence and personal experience") of social learning systems, and which is reflected in the dialectical nature of the relationship within the sociocultural context (Wenger, 2000). What is portrayed is the willingness of these two teachers to pursue and accommodate professional change within their work CoP.

The two EFL teachers participate as members of their professional CoP by engaging in collaboration with colleagues and others both within and outside the school context. For example, teachers in Maharashtra are required to participate in in-service teacher training outside the school context when the syllabus is modified every five years. The sharing of knowledge and skills among the participating teachers and teacher trainers was considered to be a bonus in attending such programs. However, Mrs. So was unable to attend any in-service teacher training to date as she had been on maternity leave.

\section{Sociocultural context}

The state of Maharashtra in India is bordered by the Sahyadri mountain range of the Western Ghats, the Deccan plateau and the river valleys to the east. Maharashtra is one of the most economically advanced states of India which hosts a vibrant urban industry and rural agriculture (Sinclair, 1995, p.130). The city of Pune is located in Maharashtra and the Pune culture has strong ties to both Hinduism and the caste system. The Pune sociocultural context is culturally and linguistically rich with values and practices of a historical nature. The local Pune culture exhibits the features of a collectivist culture as it places a high value on family and community rather than on the individual (Toraskar, 2015).

The implicit expectation in collectivist cultures is that any successful relationship evolves over time into a more personal one (Ageyev, 2003, p.439) and this underscores the engagement of the two EFL teachers, namely Mr. L and Mrs. So in their professional community of practice. Therefore, every social interaction originates as a formal, official relationship and evolves into a more personal, dynamic relationship. The interactions which evolve between the EFL teachers, students, colleagues, school administrators and the local community exemplify the relationships which exist in a collectivist culture. The formal teacher-student relationships observed in the EFL classroom stand in stark contrast to the warm 
rapport between teachers and students outside of the classroom and are characteristic of a collectivist culture (Toraskar, 2015). Thus, in the Pune culture, it is the social group to which one belongs which takes precedence over the individual's needs and which forges strong ties to both the immediate and extended family and also the local community. This notion of "cultural inclusiveness" is best expressed in the ancient Indian concept of vasudhaiva kutumbakum which means that the world is one family (Dasgupta and Lal, 2007).

\section{The changing view of English}

It is essential to examine the metamorphosis of the public's view of English in order to fully understand the sociocultural context in which these two teachers live their professional lives. From the early 1800's beginning with the arrival of the missionaries, India has witnessed a rise in the use of the English language in areas such as administration, judiciary and the medium of education (Agnihotri, 2007).The sociocultural context of the past had labeled the English language as the language of the colonizers and a language which belongs to the firangi (i.e. foreigner). English was used as a symbol of prestige among the elite as a means of exploitation of the masses. Although the historical sociocultural context thus described is not erroneous, today a new view has emerged helped along by the emergence of information technology and India's developing economy. The view of 'English as a colonizer's language' has been replaced with the view of 'English as a tool of economic empowerment and social equality' for all, especially the poor.

Krishnaswamy and Krishnaswamy (2006) support the view that English is the language of the world-wide web and the Info-Age. They claim that the Indian mindset has shifted away from the view of English as a beacon of colonialism. Today, Hindi is recognized as an "intranational lingua franca" and official language, whereas English is regarded as an "associate official language" and an "international lingua franca" (Agnihotri, 2007, p. 199). English is now perceived as a tool with which to communicate internationally and to locate job opportunities in the global market. The Indian public nowadays perceives English as a "culturally neutral tool of communication" (p. 158). The possibility of future economic prosperity has removed the fear that the learning of English endangers the Indian identity and results in westernization. The highly-valuable market skills of the twenty-first century require individuals to have strong oral and written English communication skills essential for lucrative employment such as call-centre jobs, a fact which the public has clearly understood.

Knowledge of Pune community life, both past and present, its customs, values and practices are essential for the EFL teacher. The degree to which such information can be successfully integrated into the daily teaching of EFL is an indicator of the skill and knowledge of the teacher to adapt the textbook content 
to the lesson and to use relevant examples from the sociocultural context to generate student interest in the content of the lesson (Toraskar, 2015).

\section{The families}

Many of the parents in the school are employed as farmers, street-vendors or maids and their children may be the first in the family to have completed a tenth standard education. The farmers' children are usually required to work on the farm or at home and are not encouraged to continue with their education which is a financial burden for the family. Female students are married at an early age and are more likely not to be encouraged by their families to proceed beyond tenth standard. However, the parents are now beginning to realize the importance of the tenth standard SSC examination.

Mr. L and Mrs. So identify and attend to the needs of their students' parents, which are as equally important as the SSC (i.e. tenth standard Secondary School Certificate) examination results. For some parents, the EFL lesson is much more than simply good SSC examination results. They know that today English is 'the language of the world' and 'the language of the internet' and that it can free their family from the cycle of poverty in which they live. In addition, the parents want their children to be sufficiently educated to be able to use the language in practical situations such as in the banks and post offices in Maharashtra. Furthermore, the child's ability to use English is a matter of parental pride as their child can be publicly seen and heard using English which was once a symbol of the elite in society. Consequently, both the parents and the teachers do not place much value in teacher awards, such as the 'Ideal Teacher Award' but instead look towards the financial and career opportunities which a sound knowledge of the English language offers students.

\section{The Pune School}

The Marathi-medium secondary school in this study is located in the semi-rural Pune district of Maharashtra and the school is affected by the socio-economic conditions of the surrounding area. These socio-economic conditions impact the schools and the teachers who are employed in these schools by presenting a range of challenges in providing quality education for the students. For example, Marathi-medium schools are state funded and usually financially underfunded. The school principals must depend on their own resources and imagination to fund the school even if this involves collecting door-to-door donations from the local community. Although today the area is developing economically, limited opportunity still exists in acquiring school donations from either local families or businesses compared to schools in economically developed areas of the Pune district. 
The influence of the MoI on students extends beyond classroom instruction and the SSC examination. Marathi students who cannot communicate in English experience difficulty succeeding in job interviews where some questions are asked in English. Their low level of English language proficiency limits their employability and career choices and traps them in a cycle of poverty, depriving them of the opportunity to benefit from India's emerging economy. Thus, it is unsurprising that educators at all levels and parents are eager for students to reap the perceived benefits of the English language. At a societal level, these students must amass the skills, particularly in English, to participate in and support the infrastructure which India badly needs to move into the competing global markets of the twenty-first century.

\section{The tenth standard EFL teachers}

The teachers who work in Marathi-medium government schools are overworked and underpaid and may even lack teaching qualifications. Class size in the semi-rural areas of Maharashtra may range from forty to fifty students. The teachers who work in these schools have received a Marathi-medium education and the school is staffed by Maharashtrians. The tenth standard syllabus which is designed by the Maharashtra State Board of Secondary and Higher Education in Pune is fast-paced and heavy in semester one to accommodate the revision schedule in semester two and the many local festivals and school activities. As a result, the tenth standard teachers must complete the teaching of one unit from the EFL coursebook each month until all units are covered. They are required to teach additional EFL lessons to cover the syllabus between June and December so that students can take the SSC examination in March in semester two.

The necessity for students to use and hear English in class is propagated by the Pune B.Ed. program which insists on English-only classrooms and the exclusion of the regional languages. During classroom observations, school officials pay attention to the medium of instruction used in the EFL lesson. However, the tenth standard classroom reality involves using both English and Marathi in Marathimedium secondary schools (Toraskar, 2015). Interestingly, school officials use the Mol as a measure of the teacher's knowledge and ability to teach the English language. Teachers are evaluated using the Teacher's Confidential Report form which asks the headmaster to comment (in written form) on the teacher's Mol. The EFL teachers are also assessed on their honesty, public relations and faults (if any) and classroom performance and duties 'other' than teaching. This includes their subject knowledge; ability to explain; question students; provide examples to students; motivate students; class control; discipline; relationship with students, teachers and co-workers. Other Duties include an interest in extra-curricular activities e.g. sports, PE, Scout organizations; Empathy, earnestness, loyalty and 
dedication; honesty, moral character, obedience, punctuality and punishments or rewards received

The EFL teachers in this study experience pressure to teach using only English as the MoI from various stakeholders in the Pune community. On the other hand, there is the reality of the EFL classroom where the majority of rural students experience problems with an English only classroom situation and the ensuing silence it produces. Both teachers were observed using Marathi and English at different stages of their classroom instruction. The reasons given ranged from helping students understand the lesson to keeping the students interested and motivated.

\section{In-service teacher training}

Mr. L and Mrs. So believe that participation in the in-service teacher training programs as part of their work $\mathrm{CoP}$ is an advantageous learning experience. For example, they cited learning about the changes to the syllabus and how to effect these changes in classroom instruction. In addition, the exchange of ideas among their peers and the teacher-trainers running these programs resulted in teachers developing an awareness of best teaching practices and an awareness that each teacher has their own style of teaching.

\section{B.Ed. Teacher training}

The B.Ed. qualification and a B.A. is an educational starting point for teachers in Maharashtra and it is the minimum qualification for teaching in Marathimedium secondary schools in the Pune area today. Although Mrs. So and Mr. L are supporters of the B.Ed. program as a compulsory teacher qualification (\#1, Q.18) yet they recognize that the B.Ed. program has certain inadequacies. For example, Mr. L. referred to a gap in the B.Ed. program which does not address the administrative part of a tenth standard teacher's workload. In addition, Mrs. So questioned the usefulness of the B.Ed. program for teaching tenth standard. For example, she claimed that when she was studying in the B.Ed. program, she was instructed to teach only one paragraph in each EFL lesson, to use teaching aids and to ask the students many questions. However, she now believes from drawing on her experience of teaching tenth standard students that she will not be able to finish teaching the syllabus if she adheres to the B.Ed. advice, especially as the syllabus has "Too much load.". The commonly held belief is that teachers will learn the administrative side of their work when they are employed in the secondary schools. In other words, the B.Ed. program is out of sync with the teaching reality of the school environment (Toraskar, 2015). 


\section{The relevance of the sociocultural context}

Tsui (2003) points out that the skills and knowledge which teachers develop are intimately connected to the contexts in which they work and also to the teacher's own personal background. Furthermore, there is a dialectical relationship between the development of teacher's knowledge and the specific context in which they work, which at the same time fashions the contexts in which their knowledge is formed. According to Vygotsky (1978) where the mind is considered to be an entity which is constantly changing according to the socially and culturally shaped contexts in which it finds itself at any given time, it is this participation in the social and cultural milieu which makes us what we are. Therefore an essential aspect in understanding teacher change and learning is to examine the sociocultural context in which teachers live and work.

Support for the relevance of the sociocultural context is found in the work of Sternberg and Grigorenko (1999) who conducted field research in the slums of the city of Lucknow in India. They support the stance that the contextual relevance of a research site is of extreme importance in conducting field research. In fact, Sternberg and Grigorenko are convinced that "We [researchers] have an opportunity to see life through the eyes of those whom we seek to understand." (p.20). Therefore, it is essential to understand the local context in which the teachers work and live in order to fully comprehend the transformation they experience in their professional lives.

\section{Theoretical perspectives}

One of the most significant theories to emerge from the domain of situated or social learning theory is the concept of a community of practice which has been employed not only as an explanatory framework for learning but also as a means to metaphorically explore instruction (Hoadley, 2012). Although Lave and Wenger (1991) are credited as the originators of the community of practice notion, the work of others such as Brown and Duguid (1991), Orr (1990) and Constant (1987) make reference to the concept.

Hoadley (2012) identifies two definitions emanating from Lave and Wenger's work (1991) which are defined as a 'feature-based definition' and a 'process-based definition'. The feature-based definition of a community of practice is one which adopts a more anthropological perspective of knowledge and situated learning which exists between cultures and individuals and involves practices in context. Therefore, the community shares its practices and learning is situated in a problem-solving context. It involves tacit knowledge which "could only be made explicit through social processes in the context of an actual problem." (Hoadley, 2012, p. 288). Lave and Wenger's (1991) major breakthrough which is corroborated by Orr (1990) is that learning is entrenched in cultural practices in authentic contexts of practice. 
The second definition of a community of practice attributed to Lave and Wenger is defined as a process-based definition. According to the process-based community of practice "the process of knowledge generation, application, and reproduction, is that communities of practice are groups in which a constant process of legitimate peripheral participation takes place." (Hoadley, 2012, p. 290). Learners, such as the teachers in this study, enter a community of practice and over time continuously adopt the central practices of the group in which they hold membership through their legitimate peripheral participation. This means that for learning to occur, learners must have access to expert practices and experts; the community of practice must already be in existence and have a shared history and identity (Barab \& Duffy, 1998) and learners must be afforded space for legitimate peripheral participation (Hoadley, 2012).

Wenger's (2000) conceptual framework is used to examine EFL teacher change as a process which is determined as social in nature. The rationale for adopting Wenger's social theory of learning is based on Vygotsky's (1978) theory whereby learning is fundamentally social in nature and is mediated by culture. Furthermore, at the heart of Vygotsky's theory is the principle of dialectical logic whereby the only constant is change and phenomena are viewed as "processes in motion" (Mann, 2012, p. 103). In Vygotsky's words, "To study something historically means to study it in motion. Precisely this is the basic requirement of the dialectical method." (1997, p.43).

Therefore, the activities in which Mr. L and Mrs. So engage necessitate critically examining the origin and path of development of these activities as they participate in their professional community of practice (CoP). According to Lave and Wenger, a CoP "does imply participation in an activity system about which participants share understandings concerning what they are doing and what that means in their lives and for their communities." (1991, p. 98). Therefore, Wenger (2000) defines "social competence and personal experience" as two components of social learning systems. He determines that learning occurs whenever there is tension between the two components and that it is this tension which underscores the dialectical nature of the relationship.

\section{Community of Practice (CoP)}

Communities of practice have existed wherever and whenever humans have practiced learning and knowing together. The collective nature of learning and the engagement in the process shapes and sustains a community of practice. However, learning can be the result of the interactions (or lack of interaction) between members or it may be the reason why the community is formed in the first place. The point is that learning is incidental and not intentional to a community of practice. For example, EFL teachers who interact with one another in a school 
setting may support and learn from one another and this could result in learning, yet at the same time such interactions provide emotional support for one another.

Membership in a given community of practice, of which there are many for each individual, positions each member within a community. Some members weave in and out of communities along tumultuous trajectories and exist as core or central members whereas others exist as peripheral members. Lave and Wenger (1991) claim that participation in the practices of a community is the basic, prominent feature of learning. Thus, a "community of practice" (CoP) is defined as "a set of relations among persons, activity, and world, over time and in relation with other tangential and overlapping communities of practice" (p.98). Wenger et al. (2002) identify three elements of a community of practice which are domain, community and practice. The domain element spans the every day know-how to professional expertise. Community is the interaction which occurs between people, including the learning and building of relationships within a specific environment. Lastly, practice consists of the tools, documents and ideas which the members share.

\section{Learning in a CoP}

Learning occurs regardless of whether we are novices, experts or old-timers. Learning always involves the components Wenger identified as social competence and personal experience and which he explains as "the competence that our communities have established over time (i.e. what it takes to act and be recognized as a competent member), and our ongoing experience of the world as a member (in the context of a given community and beyond)." (2000, p. 227). Therefore, this research examines the participation of Mr. L. and Mrs. So in their professional community of practice (CoP) using Wenger's three elements as a lens which define competence, i.e. joint enterprise, mutual engagement and shared repertoire. These elements are explained as follows.

Firstly, according to Wenger, competence is defined by a community of practice through the uniting of these "three elements". Therefore, "...members are bound together by their collectively developed understanding of what their community is about and they hold each other accountable to this sense of joint enterprise. To be competent is to understand the enterprise well enough to be able to contribute to it." (2000, p.229). Wenger identified the second element as mutual engagement which is how members build their community. Wenger opines that "They interact with one another, establishing norms and relationships of mutuality that reflect these interactions. To be competent is to be able to engage with the community and be trusted as a partner in these interactions." (2000, p. 229). According to Wenger, the third element he identified as a shared repertoire which is the communal resources the communities of practice have produced. These include "language, routines, sensibilities, artifacts, tools, stories, styles, etc. To be 
competent is to have access to this repertoire and be able to use it appropriately." $(2000,220)$.

\section{The study}

This study aims to illustrate the trajectories along which Mr. L and Mrs. So have traveled where learning is situated within the specific professional experiences of joint enterprise, mutual engagement and shared repertoire. The teachers' quotes are reported verbatim.

\section{Research questions}

The three research questions which guided this study were (a) what is the nature of the professional transformation, (b) what is the impetus behind the professional transformation and (c) how is the professional transformation framed within the work CoP?

\section{Methodology}

Case study methodology (Stake, 1995; Yin, 2003) was employed to examine the professional development of two tenth standard EFL teachers in a Marathimedium government-sponsored secondary school in the Pune district of Maharashtra (India). Ethnography was deemed highly appropriate due to its orientation to the understanding of culture, local contexts and the role of triangulation in incorporating different points of view (Hornberger, 1994; Davis \& Lazaraton, 1995; Strauss \& Corbin, 1990; 2008). A sociocultural approach was used to analyse the professional transformation of the EFL teachers as they live and work in the Pune context (Calderhead \& Robson, 1991; Johnston, 1994). Mr. L is an expert teacher (Toraskar, 2015) and his career trajectories placed him as a central member of the school and the teaching community in comparison with Mrs. So, a novice teacher who had less than one year of teaching experience at the time of the study. In comparison, Mrs. So is accorded periphery member status by the school and the teaching community. Thus Mr. L and Mrs. So, in their own words, illustrate their practice and the professional trajectories each teacher undertakes which are socially and culturally situated.

\section{Data sources}

The primary data set consists of one initial teacher interview for Mr. L. and Mrs. So which was approximately fifty-five minutes in length with follow-up interviews conducted approximately 40 minutes in length. One B.Ed. College teacher trainer was interviewed (i.e. currently teaching in the English college stream) from a local B.Ed. college in the Pune area (approximately 45 minutes in length); one school supervisor interview (approximately twenty-five minutes in length); one school principal interview (approximately 25 minutes). A Participant General 
Information survey, which was a 15-item survey was used to collect background information on the EFL teachers such as: age; education; number of years teaching experience; professional development; teacher training and whether they had received any awards.

On-site classroom observations were conducted for each $10^{\text {th }}$ standard EFL teacher which were videotaped. One cameraman was employed to videotape the lessons using a digital camera and focusing mainly on the teacher. Each EFL lesson recorded in the study was reviewed in India and completely transcribed verbatim in Hong Kong. Researcher notes were used as an aid in comprehending the videotapes. Semi-structured audio-taped interviews of the two EFL teachers were conducted using a semi-structured questionnaire which included questions related to the dimensions of teacher's classroom practice such as their personal convictions as influenced by their life experiences; learning and teaching experiences; academic background; professional development; pedagogical content knowledge and the dialectical relation between teachers' knowledge and their world of practice. The interviews took place on the same day as the classroom observation or one or two days later. Once transcripts had been produced for the initial interviews of the two teachers, the transcripts were then carefully read and follow-up interviews (semi-structured, audio-taped) were then conducted. In addition, various school-related artifacts were collected throughout the data collection process and these included the teachers' lesson plans, teacher evaluation forms, the tenth standard syllabus, the $10^{\text {th }}$ standard English language textbook (Third Language) and Researcher field notes.

\section{Participants}

The rational for selecting Mr. L and Mrs. So for the study was based on the particular stage of their professional lives. Furthermore, Mr. L. had been identified as an expert teacher (Toraskar, 2015) who was mid-career whereas Mrs. So was identified as a novice teacher who was at the beginning of her teaching career. A more detailed description of the two EFL teachers is provided below.

\section{Analysis}

The analysis of the semi-structured, audio-taped interview data employed Strauss and Corbin's (1998) grounded theory approach which involved open and axial coding of relevant themes associated with professional change. Furthermore, thematic analysis was conducted using the axial codes as a guide (Braun and Clarke, 2006) and pertinent themes were identified which were congruent with the research questions. The entire data analysis process was recursive in nature and involved triangulation of the data. 


\section{Findings and discussion}

The following two case studies will address the three dimensions of practice of a professional CoP in a semi-rural school in the Pune district. These dimensions include 1) joint enterprise 2) mutual engagement and 3) a shared repertoire.

\section{Case study: Mr. L}

Mr. L is identified as a central member his professional CoP who is currently teaching tenth standard secondary school students in the Pune area (Toraskar, 2015). Mr. L. is in his early forties and he had been teaching EFL for more than fifteen years. He was the English department head at the time of this study. His formal qualifications include a B.Ed., a B.A. and an M.A. in English. In addition, he had received the Ideal Teacher Award which is awarded by the Pune Municipal Corporation (PMC) to outstanding teachers in recognition of their teaching ability.

The tenth standard syllabus for English as a third language in Maharashtra is modified every five years. Changes to the syllabus necessitate the organizing and scheduling of in-service teacher training programs which are important events and where teacher attendance is mandatory. Mr. $\mathrm{L}$ is a proponent of such programs because he recognizes the potential for learning from his participation in and contribution to his professional community. In Mr. L's words: "Training programs are most important because without training programs, teachers are unable to know the new trends of the syllabus and the new techniques of the syllabus, how the paper [SSC examination paper] should be arranged and all the facts. Without training the teacher is unable to understand [the new syllabus]."(FI, Q1)

$\mathrm{Mr}$. L is explaining what Wenger defines as the joint enterprise dimension, how the communal resources are shared and also how participants contribute in shaping these resources. He understands the relevance of teachers' engaging in and working towards the common aim of comprehending the modified syllabus content, how to teach it and how the SSC examination is set. In other words, Mr. L, as a competent member of the professional CoP participates in and contributes to his professional CoP. Any modifications to the tenth standard syllabus are conveyed to teachers through participation in such training programs and a lack of attendance is discouraged.

In-service teacher training programs offer members an opportunity to strengthen and develop the CoP. According to Mr. L, "The first benefit is that other teachers [are] from different schools...Everyone has different styles, different methods, their knowledge and we can communicate with each other. So, we discuss in the training program...They are talking with each other, sharing our thoughts, techniques, methods. Everyone has some good qualities that we can get chance to learn it [best teaching practices]." (FI\#1, Q30) 
Mr. L is referring to how the teachers mutually engage with one another and the potential to learn from such interactions. He continued, "This person [teachertrainer] was telling," You [teachers] should introduce this one [topic] in this way into the class.", but we teachers try to tell that this is the way you are talking, teaching us to teach. But amongst the teachers there are some different kinds of experiences and other teacher they also confirm. And everyone's style is different and in the training program I think the discussion, because a lot of teachers from different schools, they have different ideas, with different styles. It helps them, their experiences. It is more useful for us, helpful for us." (II, 2.4)

Mr. L has learned from his experiences that the key to successful mutual engagement among teachers is grounded in communication, collaboration and the sharing of teaching-related knowledge and ideas. Competent members come into existence through their relationships of mutuality with other members of the CoP and are viewed as a trusted partner in these social interactions. At the same time it is essential to be sufficiently open-minded in accommodating any differences between members in order to fully maximize the learning potential of the situation.

Mr. L recalled how communal teaching knowledge was shared with him by his B.Ed. teacher trainer. The sharing had occurred after Mr. L was observed in class during his practicals (i.e. teaching practice) when he was teaching vocabulary. His lecturer introduced him to the specific language which EFL teachers employ during his feedback session. Mr. L said, "And that lecturer told me "Don't call it difficult word. It is a new word." I got that idea. Yes, every word is easy. You can call it new. It is new for us. That's why we think it is difficult. But that is not the difficult one. It is a new word." (FI\#2, Q.5)

$\mathrm{Mr}$. L is recalling an interaction which occurred between two members of the same CoP (i.e. the EFL teacher trainer and Mr. L) and the sharing of communal resources or in this case, jargon (i.e. new word) which facilitates student learning. Wenger referred to this activity as a shared repertoire of communal resources produced by a CoP and which now constitutes a past event or story which was shared with the researcher. It further establishes the peripheral position of Mr. L as a student-teacher compared to his lecturer who was a fully-fledged member of the teaching CoP.

\section{Case study: Mrs. So}

Mrs. So is a novice teacher and peripheral member of her professional CoP. She was in her mid-twenties and had completed only one year of tenth standard teaching at the start of this study. Mrs. So had been asked to teach tenth standard English when the school's tenth standard teacher had resigned and as a result she had faced many challenges. For example, she was afraid to teach the tenth standard syllabus although she had attained both a B.A. and a B.Ed. in English prior to her 
employment with the school. Her fear was rooted in the belief that the syllabus was 'very large' and the insurmountable pressure on her to teach within the designated timeframe. Mrs. So had not participated in any in-service teacher training courses as she had taken maternity leave after her first year of employment.

Mrs. So was a new addition to the teaching profession and as such she was not defined as a competent member of her work CoP due to her peripheral status. Therefore she relied on more competent members or 'insiders', such as the school principal, Mr. Po and Mr. L to offer positive reinforcement based on their collective understanding and sense of joint enterprise of their CoP: "My role model is the Head of our department, Mr. L sir and our principal, Mr. Po sir. They, both of two [them] always encouraged me. You do this! You do this! You have the abilities to do this so don't fear. “(FI\#2, Q.25)

Veenman (1984, p. 184) refers to novice teachers in their first year of teaching as suffering from "reality shock" when they experience the reality of the school context. This may explain Mrs. So's fear with her limited participation in her school and her professional CoP. Consequently, she relied on Mr. L and Mr. Po as more competent members to provide support and assistance which in turn verified their acceptance of her into the professional community. She was able to draw upon her interactions with these more competent members in their mentorship role to allay her fears of teaching tenth standard English and to receive positive reinforcement of her potential to fully participate in the future. It was their encouragement, support and faith in her ability as a tenth standard teacher and learning to teach that helped establish her as a new, albeit peripheral member who had the potential to become a competent member of their CoP.

Two challenges Mrs. So faced in the first year of teaching which was her lack of support and social interaction with the lower level administrative staff (i.e. peons) and her colleagues. "...But the peons, they do not listen to what I say. Then I feel very sorry. But the second year, everybody help me." (FI\#1, Q.68). Mrs. So said "They [the peons] thought that I'm going [to leave]. I'm not staying." (FI\#1, Q.69). "Because there were no English teacher for ten years. Nobody stay there" (FI\#1, Q.70).

In describing her interactions with her colleagues, Mrs. So had cited that there was no-one to whom she could turn for help other than Mr. L and Mr. Po: "So I am always, want to speak but they [other teachers] are having more, they are having more experience. So they are not tell [telling] me what I can do at that time." (FI\#1, Q. 74)

Mrs. So was willing to engage in and be recognized as a participant in her professional CoP. However, the lack of support and social interaction afforded her by the school peons and her colleagues limited her opportunity to learn. Her inability "to take part in meaningful activities, in the production of sharable 
artifacts, in community-building conversations, and in the negotiation of new situations." resulted in what Wenger (1998, p. 184) coined as "a lack of mutuality in the course of engagement [that] creates relations of marginality" (p.193). Therefore in her first year of teaching, she was not able to form meaningful interpersonal relationships with her colleagues at school which would have created a history of and mutual engagement in shared experiences. Neither was she given full access to "reificative paraphernalia of practice" (p. 184) such as document, tools, symbols and language etc.

Learning to teach the tenth standard content in an examination-oriented educational system was a challenge for Mrs. So. She depended on Mr. L to share with her the communal resources which would help her learn and overcome any of her difficulties. She stated that "We talk about some essays, which essays we give for which standard. Mr. L is a very experienced teacher so I always discuss about the syllabus. [If] I have any problem of any words, I discuss and the homework, which homework, how many homework." (FI\#2, Q.18)

Mrs. So is referring to the shared repertoire or resources of tenth standard teaching which is characteristic of practice in her work CoP. For example, tenth standard teachers habitually give their students homework. How much homework to give to students and how often is part of the tenth standard teaching practice. Thus, this routine of giving students homework is part of the repertoire of her work CoP which has been adopted as part of its practice.

To sum up, decades of research on teacher's professional development shows that the expectations placed on novice teachers from the first day of their employment in schools means that they are expected to perform the same duties required of experienced teachers. Clearly, novice teachers like Mrs. So have less time for lesson preparation and to reflect on their teaching practice. Mrs. So had difficulty obtaining administrative and collegial cooperation and learning the ropes'. Mr. L is shown to be a competent member of his CoP who contributes to his professional CoP through his participation in in-service teacher training events and shares what he learns with Mrs. So. It is essential for novice teachers to actively engage in discourse on shared strategies and problem solving through legitimate peripheral participation (Lave and Wenger, 1991) and social interaction among colleagues which will result in effective, professional change in practice.

\section{Conclusion}

In conclusion, this article has attempted to draw upon real-life examples from the sociocultural context which illustrate the trajectories of two tenth standard EFL teachers who are at different stages in their professional development and how they participate in their professional CoP. The aim was to answer the three research questions in this study which were (a) what is the nature of the professional transformation, (b) what is the impetus behind the professional 
transformation and (c) how is the professional transformation framed within the work CoP? Firstly, this study indicates that the source of professional tenth standard teacher change is rooted in the desire to participate as a fully-fledged core member of the CoP. Furthermore, the motivation to change originates from the drive to learn how to be a contributing member of the CoP. Lastly, professional change can only occur when the teachers are offered the opportunity to participate in and benefit from social interactions, either formal and/or informal, within a professional $\mathrm{CoP}$ where learning and exchange of ideas and information which can be applied to classroom reality are at the forefront of their professional development. Most notably, the two case studies support the view that the nature of the EFL teachers' professional change is 'adaptive or fluid' (Berliner, 2001) and that it is in a constant process of transformation as it interacts with the sociocultural context.

Today, the Indian classroom poses a challenge for teachers regardless of their qualifications given the large class size, first-generation learners and the lack of resources (OECD, 2011). In view of the urgent call for effective teacher training and teacher professional development (OECD, 2011, 2005), the findings of this study concretely support the existence of professional communities of practice which offer a practical solution to teacher development.

\section{References}

Ageyev, V.S. (2003). Vygotsky in the mirror of cultural interpretations. In A. Kozulin, B. Gindis, V. Ageyev \& S.M. Miller (Eds.). Vygotsky's Educational Theory in Cultural Context (pp. 432-50).

Barab, S. \& Duffy, T. (1998). From practice fields to communities of practice (pp. 31). Bloomington, IN: Center for Research on Learning and Technology. CRLT TechnicalReport 1-98, http://crlt.indiana.edu/publications/duffy publ3.pdf [accessed 23 May, 2016].

Berliner, D.C. (2001). Learning about and learning from expert teachers. International Journal of Educational Research, 35(5), 463-482.

Braun, C. \& Clarke, V. (2006). Using thematic analysis in psychology. Qualitative Research in Psychology, 3(2), 77-101.

Brown, J. S. \& Duguid, P. (1991). Organizational learning and communities-ofpractice: Toward a unified view of working, learning, and innovation. Organization Science, 2(1), 40-57.

Calderhead, J. \& Robson, M. (1991). Images of teaching: Student teachers' early conceptions of classroom practice. Teaching and Teacher Education, 7, 1-8.

Constant, E.W. II (1987). The social locus of technological practice: Community, system, or organization? In W.E. Bijker, T.P. Hughes \& T.J. Pinch (Eds.). The social construction oftechnological systems (pp. 223-242). Cambridge, MA: MIT Press. 
Corbin, J. \& Strauss, A. (2008). Basics of qualitative research: Techniques and

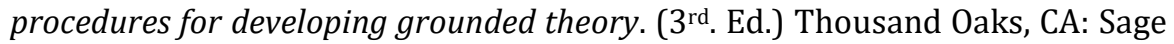
Publications Inc.

Dasgupta, S., \& Lal, M. (2007). The Indian family in transition: Reading literary and cultural texts. New Delhi, India: SAGE Publications.

Davis, K. \& Lazaraton, A. (1995). (Eds.) Qualitative Research in ESOL [Special Issue] TESOL Quarterly, 29(3).

Hill, S. \& Chalaux, T. (2011), Improving access and quality in the Indian education system, Economics Department Working Papers. No. 885, OECD Publishing. http://dx.doi.org/10.1787/5kg83k687ng7-en.

Hoadley, C. (2012). What is a Community of Practice and How Can We Support It? In D. Jonassen \& S. Land (Eds.) Theoretical foundations of learning environments (pp. 287-300). NewYork, NY: Routledge.

Hornberger, N.H. (1994). Ethnography. In A. Cumming (ed.) Alternatives in TESOL research: Descriptive, interpretive, and ideological orientations. TESOL Quarterly, 28, 687-703.

Johnston, M. (1994). Contrasts and similarities in case studies of teacher reflection and change.Curriculum Inquiry, 24, 9-26.

Krishnaswamy, N. \& Krishnaswamy, L. (2006). The story of English in India. New Delhi: Foundation Books Pvt. Ltd.

Lave, J. \& Wenger, E. (1991). Situated Learning: Legitimate Peripheral Participation. Cambridge University Press.

Mann, H, (2012). Vygotsky's Analysis of Children's Meaning Making Processes.

International Journal of Educational Psychology, 1(2), 100-126.

OECD (2005), Teachers matter: Attracting, developing and retaining effective teachers, OECD, Paris.

Orr, J. E. (1990). Sharing knowledge, celebrating identity: Community memory in a service culture. In D. Middleton \& D. Edwards (Eds.). Collective remembering (pp. 169-189). Newbury Park, CA: Sage Publications.

Sinclair, T. (1995). India (1 ${ }^{\text {st }}$ Ed.) Hong Kong: Twin Age Ltd.

Stake, R.E. (1995). The art of case study research. Thousand Oaks, CA: Sage Publications.

Strauss, A.M. \& Corbin, J. (1990). Basics of qualitative research. Newbury Park, CA: Sage.

Strauss, A.M. \& Corbin, J. (1998). Basics of qualitative research: Techniques and procedures for developing grounded theory. ( $2^{\text {nd }}$ Ed.) Thousand Oaks, California: Sage Publications.

Sternberg, R.J., \& Grigorenko, E.L. (1999). A smelly $113^{\circ}$ in the shade, or, why we do field research. APS Observer, 12(1), 10-11, 20-21.

Toraskar, H.B. (2015). A sociocultural analysis of English language teaching expertise in Pune, India. The University of Hong Kong. Unpublished Dissertation. 
Tsui, A. B. M. (2003). Understanding expertise in teaching: Case studies in ESL teaching. Cambridge, UK: Cambridge University Press.

Tsui, A. B. M. \& Tollefson, W. (2007). Identity and multilinguality: The case of India. In A. B. M. Tsui \& W. Tollefson (Eds.) Language Policy, Culture, and Identity in Asian Contexts (pp. 185-204). Mahwah, NJ: Lawrence Erlbaum Associates, Inc.

Veenman, S. (1984). Perceived problems of beginning teachers. Review of Educational Research, 54, 143-178.

Vygotsky, L. S. (1978). Mind in Society: The Development of Higher Psychological Processes. Cambridge, MA: Harvard University Press.

Vygotsky, L. S. (1997b). The collected works of L. S. Vygotsky: Vol. 4. The history of the development of higher mental functions. R. W. Rieber and A. S. Carton (Eds.). New York: Plenum.

Wenger, E. (1998). Communities of practice: Learning, meaning and identity. Cambridge, UK: Cambridge University Press.

Wenger, E. (2000). Communities of practice and social learning systems. Organization, 7(2), 225-246.

Wenger, E.C., McDermott, R., \& Snyder, W.C. (2002). Cultivating communities of practice: Aguide to managing knowledge. Cambridge, USA: Harvard Business School Press.

Yin, R. (2003). Case study research: Design and methods. ( $3^{\text {rd }}$ Ed.). Thousand Oaks, CA: Sage.

\section{Contact}

Dr. Helen B. Toraskar

Associate Professor,

Language and Communication

Centennial College (HKU Group)

3 Wah Lam Path, Pokfulam, Hong Kong

Helen.toraskar@centennialcollege.hku.hk 